\title{
DEZ ANOS DAS LICITAÇÕES SUSTENTÁVEIS NO BRASIL: DISTÂNCIA ENTRE A PREVISÃO LEGAL E A PRÁTICA
}

\author{
TEN YEARS OF SUSTAINABLE BIDDING IN BRAZIL: \\ DISTANCE BETWEEN LEGAL PROVISION AND PRACTICE
}

\section{Lucas Ribeiro Ferraz}

Mestre em Gestão e Estratégia pela Universidade Federal Rural do Rio de Janeiro (Seropédica/Brasil). Técnico em Assuntos Educacionais no Instituto Federal de Educação, Ciência e Tecnologia do Rio de Janeiro (Paracambi/Brasil).

E-mail: lucas.ferraz@ifrj.edu.br 


\section{RESUMO}

Com a alteração do artigo $3^{\circ}$ da Lei n 8.666/1993 ocorrida em 2010, a legislação brasileira efetivamente passou a prever a realização das denominadas licitações positivas como instrumento de promoção do desenvolvimento nacional sustentável, utilizando-se do poder regulatório e econômico do Estado. Portanto, tratando-se de política pública de incentivo à produção e ao consumo de bens, obras e serviços que ocasionem menores impactos durante seu ciclo de vida. 0 estudo objetivou analisar as legislações que versam sobre práticas e critérios sustentáveis, principalmente aquelas promulgadas nos últimos dez anos, e buscou-se realizar o levantamento das compras homologadas pelos órgãos do Poder Executivo Federal entre os anos de 2014 a 2019. A metodologia utilizada foi a pesquisa bibliográfica e documental e os dados foram coletados em meio eletrônico (legislações) e no site Portal de Compras do Governo Federal (licitações). No tratamento dos dados, empregou-se a técnica de Métodos Mistos. Os resultados apontaram a evolução das legislações existentes no ordenamento jurídico nacional e os baixos índices de compras públicas sustentáveis computadas, o que demonstra o distanciamento entre a previsão legal e o ocorrido na prática. Verificou-se o crescimento percentual das compras sustentáveis no período pesquisado, mas estas ainda podem ser consideradas incipientes no Brasil.

Palavras-chave: Desenvolvimento sustentável. Licitação sustentável. Política pública.

\section{ABSTRACT}

With the amendment of article 3 of Law 8.666/1993 that occurred in 2010, Brazilian legislation effectively started to provide for the holding of so-called positive tenders as an instrument to promote sustainable national development, using the regulatory and economic power of the State. Therefore, in the case of a public policy to encourage the production and consumption of goods, works and services that cause less impact during their life cycle. The study analyzed the laws that deal with sustainable practices and criteria, especially those enacted in the last ten years, and carried out a survey of purchases approved by the Federal Executive branches between 2014 and 2019. The methodology used was bibliographic research and documentary, data were collected electronically (legislation) and on the Federal Government's Purchasing Portal website (bidding). In the treatment of the data, the Mixed Methods technique was used. The results obtained pointed to the evolution of existing laws in the national legal system and the low rates of sustainable public procurements made, which demonstrates the gap between the legal provision and the assisted in practice. There is a percentage increase in sustainable purchases in the surveyed period, but these can still be considered incipient in Brazil.

Keywords: Sustainable development. Sustainable bidding. Public policy. 


\section{INTRODUÇÃO}

A preocupação com a preservação dos recursos naturais tem assumido maior relevância no debate internacional nas últimas décadas, especialmente devido à dinâmica de produção e consumo considerada acima das capacidades de reposição do planeta (VEIGA, 2010). Neste cenário, a Organização das Nações Unidas (ONU), por meio do Relatório de Brundtland(1987), observou a urgência de estabelecer parâmetros para o desenvolvimento sustentável, sendo definido como "[...] aquele que atende às necessidades do presente sem comprometer a capacidade de as gerações futuras atenderem as suas próprias necessidades" (COMISSÃO MUNDIAL, 1991, p. 46).

A busca pelo equilíbrio entre as dimensões econômica, social e ambiental - tripé da sustentabilidade - visa conciliar as demandas contemporâneas, com a redução dos impactos negativos gerados pela ação humana. Portanto, a adoção de políticas públicas orientadas a racionalização do uso dos recursos naturais disponíveis e o engajamento social podem ser entendidos como pilares do desenvolvimento mais responsável (LALOE, 2014).

No Brasil, as compras públicas somam relevante percentual do Produto Interno Bruto (PIB), com o Ministério da Economia estimando valores entre 10 a 15\% do PIB nacional (BRASIL, 2020). Portanto, pode-se inferir a capacidade dos órgãos governamentais estimularem o mercado verde, especialmente, pelo poder regulatório (promulgação de normas legais) e econômico a partir da geração de demanda por bens e serviços que ocasionam menores impactos ambientais e sociais no decorrer do ciclo de vida.

A delimitação conceitual da pesquisa está pautada no entendimento do Estado como principal agente de fomento das políticas públicas capazes de incentivar o desenvolvimento nacional sustentável DNS. Neste contexto, o trabalho tem como objetivo estudar os dados das compras realizadas pelo Poder Executivo Federal, verificando se estas aquisições estão atendendo aos preceitos legais e aos interesses sociais relacionados à promoção da sustentabilidade. A pesquisa se justifica pela relevância teórica e prática do tema abordado, conduzindo-se análise dos dados sobre as licitações positivas homologadas no período de 2014 a 2019.

O estudo tem a pretensão de contribuir com indicadores numéricos capazes de avaliar o atual estágio das ecoaquisições nacionais, ou seja, apresentando elementos quantitativos capazes de demonstrar o baixo índice de efetivação registrado no espaço amostral investigado. Deste modo, somando-se novos elementos a discussão teórica existente, dada a originalidade da presente pesquisa. Segundo Biderman et al. (2008), a licitação positiva também pode ser denominada como compra pública sustentável, ecoaquisição, compra verde ou licitação sustentável. 
O artigo está estruturado nas seguintes seções. Introdução, incluindo a contextualização do tema, delimitação, objetivo e justificativas do trabalho. O Referencial teórico abordando as Origens e Contexto da Sustentabilidade, as licitações como instrumento de promoção do Desenvolvimento Nacional Sustentável e a Evolução das legislações que versam sobre o assunto. Metodologia empregada no estudo. Discussão dos resultados obtidos mediante pesquisa documental. As Considerações Finais do estudo. E, por fim, as Referências.

\section{ORIGENS E CONTEXTO DA SUSTENTABILIDADE}

A degradação ambiental é uma pauta importante no debate público, questionando os padrões de produção e consumo observados em todo o mundo. Desde a década de 1970, mais especificamente após a Conferência das Nações Unidas sobre o Meio Ambiente realizada na cidade de Estocolmo (1972), os representantes dos países presentes iniciaram o debate sobre a conservação dos recursos naturais, apontando para a necessidade de rever os limites do desenvolvimento e os padrões de consumo e produção mundial assistidos a época, assim visando conciliar o avanço econômico com a manutenção do equilíbrio ambiental (NASCIMENTO, 2012).

A partir da primeira conferência, a ONU vem realizando outras ações no mesmo sentido, com destaque para:

- O Relatório de Brundtland(1987), também conhecido como Nosso Futuro Comum, é documento no qual o termo desenvolvimento sustentável foi definido e difundido no debate internacional (VEIGA, 2010);

- A Rio 92, Conferência da ONU sobre Meio Ambiente e Desenvolvimento realizada na cidade do Rio de Janeiro (1992), nesta oportunidade foram publicadas a Declaração do Rio e a Agenda 21, ambas voltadas ao estímulo de ações voltadas ao desenvolvimento sustentável (NASCIMENTO, 2012);

- A Rio+10, Cúpula Mundial sobre Desenvolvimento Sustentável realizada na cidade de Johanesburgo (2002) caracterizada pela busca de ações voltadas a construção de uma economia mais verde e inclusiva, por meio de processos mais racionais de produção e consumo (BETIOL et al., 2012);

- A Rio+20, Conferência da ONU sobre Desenvolvimento Sustentável realizada na cidade do Rio de Janeiro (2012), trazendo à discussão aspectos relacionados ao consumo, governança global, sustentabilidade urbana e economia verde, sendo estipulada uma nova meta para os próximos 10 anos (SUGAHARA; RODRIGUES, 2019). 
Neste cenário de crise ambiental de proporções globais, discutiu-se a adoção de políticas voltadas a redução do impacto exercido pelas atividades humanas, transformando o atual paradigma predatório para um desenvolvimento mais equilibrado, por meio da redução e melhor gestão dos resíduos, diminuição da emissão de gases nocivos a atmosfera, racionalização do consumo dos recursos naturais, economia de energia, dentre outras medidas. Estas ações urgentes devem ser adotadas para a definitiva ruptura com os atuais padrões de produção e consumo, assim proporcionando um futuro mais promissor às próximas gerações (BIDERMAN, 2008).

Contudo, para uma efetiva transformação do contexto supracitado, é imprescindivel o engajamento do poder público e da sociedade na adoção de diferentes ações que também valorizem os aspectos ambientais e sociais, assim podendo adotar um modelo de desenvolvimento mais sustentável (LIMA; AMÂNCIO-VIEIRA; ROMAGNOLO, 2018). Neste sentido, visto o elevado montante financeiro movimentado, destaca-se o poder de compra dos órgãos Federais, Estaduais e Municipais como uma importante ferramenta de orientação de mercado, com isso estimulando a fabricação de produtos com materiais sustentáveis e a execução de obras e serviços de forma mais limpa, por meio do uso de técnicas ecoeficientes (FERNANDES, 2019).

\section{LICITAÇÕES E O DESENVOLVIMENTO NACIONAL SUSTENTÁVEL}

O processo licitatório é procedimento administrativo prévio a efetivação das contratações governamentais, celebrando o ajuste de vontades entre o ente público e o licitante, em estrita conformidade com os princípios básicos e legislações vigentes (MEIRELLES, 2016). Na lei geral de licitações e contratos (Lei n 8.666/1993) são definidas as finalidades básicas das compras públicas, ou seja, obter a proposta mais vantajosa para a Administração e promover o DNS, observada a garantia da isonomia entre os licitantes.

Nos trabalhos de Alencastro, Silva e Lopes (2014), Couto e Coelho (2015), Oliveira e Santos (2015) e Gallon et al. (2019) a licitação sustentável é fundamentada na ideia de pensar além da aplicação imediata do recurso público, portando não buscando somente pelo menor preço. Os autores afirmam que a Administração também deverá ter atenção aos custos ambientais, sociais e econômicos advindos da aquisição de bens e serviços que causam maior impacto, sejam nas etapas de extração, produção, utilização e descarte.

Nas contratações públicas, os critérios e práticas sustentáveis devem estar previstos nos instrumentos convocatórios, assim atendendo aos princípios licitatórios e estabelecendo de forma objetiva a constituição dos bens e serviços pretendidos (MEIRELLES, 2016). Para a especificação sustentável dos 
objetos são aceitos aspectos que privilegiam a maior geração de empregos, a eficiência energética, uso de reciclados, tecnologias limpas, matérias-primas de origem local, dentre outros (ABREU, 2016).

A inclusão da promoção do desenvolvimento nacional sustentável como um dos objetivos das compras públicas, ao lado da seleção da proposta mais vantajosa, está alinhada a preocupação mundial de buscar reduzir a pressão exercida sobre os recursos naturais e os impactos ambientais e sociais gerados pelas ações humanas (BETIOL et al., 2012).

Autores como Brammer e Walker (2011), Severo, Dorion e Guimarães (2020), Caldas e Nonato (2013), Fernandes (2019) apontam a importância do Estado como potencial agente transformador das atuais relações de produção e consumo, com vistas ao desenvolvimento mais sustentável. A possibilidade da implementação de políticas públicas orientadas neste sentido decorre, especialmente, do poder regulatório, de fomento e econômico exercido pelos órgãos governamentais.

Brammer e Walker (2011) propuseram o modelo conceitual das influências sobre as licitações sustentáveis - Figura 1, elencando o contexto da política nacional como instrumento necessário a efetivação de contratações públicas sustentáveis. Ainda segundo os autores, existem quatro fatores intermediários que influenciam no sucesso das ecoaquisições, todos relacionados direta ou indiretamente às pressões e incentivos governamentais.

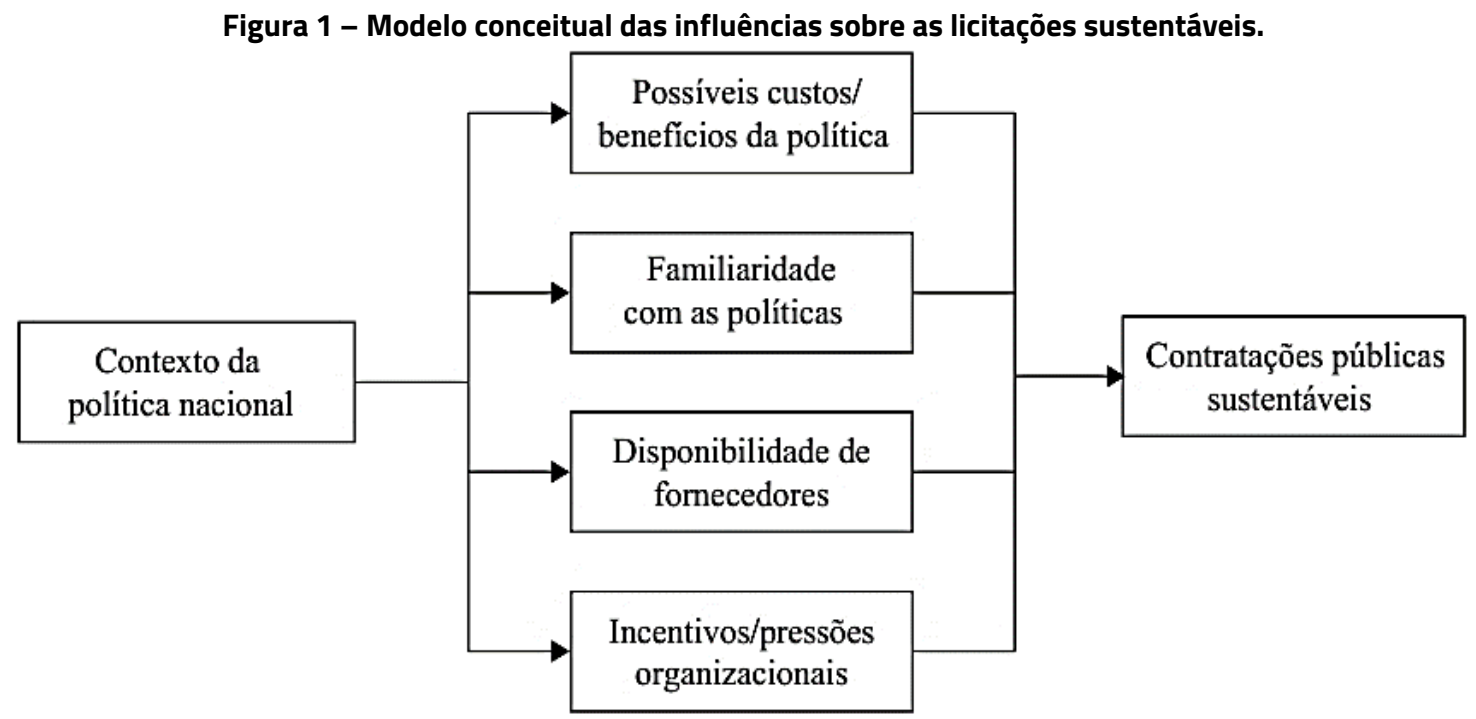

Fonte: Traduzido de Brammer e Walker (2011).

No entanto, ainda são observadas barreiras na implementação das licitações sustentáveis como prática recorrente no Brasil. Apesar da responsabilidade dos órgãos governamentais como agentes de implantação das políticas públicas, estes encontram dificuldades relacionadas, por exemplo, a cultura 
organizacional resistente a mudanças e a baixa capacitação dos servidores envolvidos nos processos de compra (COUTO e RIBEIRO, 2016).

\section{EVOLUÇÃO DAS LEGISLAÇÕES SOBRE SUSTENTABILIDADE}

As compras públicas no Brasil devem ser pautadas na preocupação de promover o desenvolvimento nacional sustentável, considerando, ao menos, os pilares ambiental, social e econômico, sem distinção entre eles (BIDERMAN et al., 2008). Importante destacar que a Constituição Federal de 1988, em especial no Artigo 22, XXVII, Artigo 37, XXI, Artigo 173, § 1 III e Artigo 175, caput, fornece as bases legais para a implementação das legislações positivas.

Com a promulgação da Lei n 6.938/1981 (dispõe sobre a Política Nacional do Meio Ambiente), a legislação brasileira passa a buscar a promoção do equilíbrio entre o avanço socioeconômico do país e a manutenção do equilíbrio ecológico. Assim, estimulando práticas que valorizam o uso racional dos recursos disponíveis, a restauração do habitat, o desenvolvimento de meios de produção mais eficientes e de novas tecnologias (BETIOL et al., 2012).

De acordo com Di Pietro (2016), a Lei n 6.938/1981 pode ser entendida como o embrião das licitações sustentáveis no Brasil, expressando a capacidade do Poder Público em orientar o mercado, a partir da sua força regulatória e do volume financeiro das suas contratações.

Após o advento da lei supracitada e sobre a égide da Constituição Federal de 1988, outras normas legais e infralegais foram promulgadas visando regulamentar diferentes aspectos da sustentabilidade, como a Lei n 9.605/1998 (Lei de Crimes Ambientais), a Lei n 10.295/2001 (dispõe sobre a Política Nacional de Conservação e Uso Racional da Energia), Lei n 11.284/2006 (dispõe sobre a gestão de florestas públicas para a produção sustentável), a Lei Complementar n 123/2006 (Estatuto Nacional da Microempresa e da Empresa de Pequeno Porte) e a Lei n 12.187/2009 (Política Nacional sobre Mudança do Clima).

Contudo, para Laloe (2014) e Abreu (2016) o ponto efetivo na normatização das compras sustentáveis é a promulgação da Lei n 12.349/2010 (introduz o conceito de desenvolvimento nacional sustentável no artigo $3^{\circ}$ da Lei n 8.666/1993), da Instrução Normativa SLTI/MPOG nº 01/2010 (disciplina a inclusão de critérios de sustentabilidade ambiental nas especificações dos objetos das licitações dos órgãos da Administração Federal direta e indireta, e do Decreto n 7.746/2012 (regulamenta o art. $3^{\circ}$ da Lei $n^{\circ}$ 8.666). Segundo os autores, a partir destas três normas o legislador impôs a obrigatoriedade da realização das ecoaquisições no ordenamento jurídico brasileiro. 
Embora tardia, se comparada ao Reino Unida, Suécia e Itália, as compras públicas sustentáveis (CPS) têm assistido a consideráveis e constantes avanços no tocante a evolução das legislações (BIDERMAN et al., 2008). Destarte, proporcionando respaldo jurídico e subsídios aos gestores públicos, tendo em vista a previsão expressa para a realização das ecoaquisições (DI PIETRO, 2016).

Veiga (2010), Nascimento (2012) e Sugahara e Rodrigues (2019) apontam que a origem dos debates acerca do desenvolvimento sustentável remonta a década de 1970, como resposta aos níveis de poluição registrados à época. Segundo os referidos autores, as discussões sobre os aspectos da sustentabilidade têm evoluído, ou seja, sendo incluídas novas tendências e demandas, extrapolando o tripé ambientalsocial-econômico.

Neste sentido, com o advento da Agenda 2030 das Nações Unidas, o conceito de desenvolvimento sustentável é ampliado para os eixos: Paz, Pessoas, Planeta, Prosperidade e Parcerias (AGENDA 2030). Logo, a dinâmica de maturação social da sustentabilidade impõe desafios ao legislador nacional, pois se deve buscar a adequação das normas às necessidades contemporâneas da população.

\section{METODOLOGIA}

A metodologia utilizada na construção da presente pesquisa teve como base os trabalhos de Creswell (2014) e Gil (2010). O delineamento utilizado foi a pesquisa documental, sendo precedido de pesquisa bibliográfica para fundamentação teórica e levantamento de informações relevantes ao trabalho. Para a coleta dos dados foi utilizado o exame documental realizado em meio eletrônico (legislações) e no site Portal de Compras do Governo Federal (licitações). A análise dos dados foi efetuada com o emprego de Métodos Mistos, combinando a técnica qualitativa na avaliação das legislações e a abordagem quantitativa no tratamento dos números das licitações.

As leis, decretos, portarias e instruções normativas, que versam sobre critérios e práticas sustentáveis, foram reunidas por meio de pesquisa bibliográfica realizada em Artigos científicos e nos Guias e Manuais dos Órgãos de Fiscalização e Controle. O levantamento bibliográfico foi realizado durante pesquisa de Mestrado (de 04/2018 a 02/2020) que, dentre outros resultados, demonstrou a evolução dos marcos normativos das licitações positivas no Brasil, no período de 1981 a 2018. No entanto, dado o foco deste estudo, foram elencadas as legislações mais abrangentes promulgadas nos últimos 10 anos (2010 - 2019).

Dado o espaço amostral do trabalho, apenas foram estudadas as legislações e reunidos dados sobre as licitações em âmbito Federal. Mas, vale lembrar que todos os entes federativos (Estados, Distrito Federal e Municípios) devem proceder com as compras verdes e ambos detêm autonomia para editar normas complementares. 
O Portal de Compras do Governo Federal é sitio eletrônico mantido pelo Ministério da Economia e agrupa diferentes informações sobre as licitações homologadas pelos órgãos pertencentes ao Poder Executivo Federal (PEF). O site foi escolhido como fonte de consulta devido à facilidade em obter as informações e por conter parcela significativa das aquisições brasileiras, tendo em vista que o PEF detém maior fatia do orçamento público. Vale ressaltar que, na época da pesquisa, o site reunia informações sobre as licitações homologadas nos períodos de janeiro de 2014 a dezembro de 2019.

Do portal, foram extraídos os seguintes dados: valor total homologado, processos totais, percentual de material e serviço, percentual destinado às microempresas (ME) e empresas de pequeno porte (EPP), compras com itens sustentáveis (CCIS), valor dos processos com critérios sustentáveis (PCCS) e o número de PCCS. As informações foram reunidas com o uso de planilhas do Microsoft Excel, sendo organizadas por unidade da federação (UF) e, por fim, consolidadas em conjunto (Brasil).

\section{RESULTADOS E DISCUSSÕES}

A normatização das licitações sustentáveis no Brasil, apesar de legislações que datam da década de 1980, tornou-se efetiva no ano de 2010, após a promulgação da Lei n 12.349/2010 e posteriores regulamentações advindas da Instrução Normativa SLTI/MPOG nº 01/2010 e do Decreto nº 7.746/2012. A partir deste marco regulatório, outras normas foram sendo adicionadas ao ordenamento jurídico nacional.

O Quadro 1 contém exemplos de legislações promulgadas nos últimos 10 anos, ou seja, após a alteração do artigo $3^{\circ}$ da Lei n 8.666/1993. Analisando as normas, entende-se que o Poder público visou expandir a produção e o consumo mais sustentável, especialmente, fazendo uso do seu poder regulatório e por meio de geração de demanda por bens e serviços, a partir de suas contratações.

Quadro 1 - Exemplo de legislações sobre sustentabilidade promulgadas nos últimos 10 anos.

\begin{tabular}{|c|c|}
\hline Ano & Legislação \\
\hline \multirow{5}{*}{2010} & $\begin{array}{l}\text { Instrução Normativa SLTI/MPOG n 01/2010: Dispõe sobre os critérios de sustentabilidade ambiental na aquisição } \\
\text { de bens, contratação de serviços ou obras pela Administração Pública Federal direta, autárquica e fundacional e dá } \\
\text { outras providências. }\end{array}$ \\
\hline & $\begin{array}{l}\text { Portaria SLTI/MPOG nº 02/2010: Dispõe sobre as especificações padrão de bens de Tecnologia da Informação no } \\
\text { âmbito da Administração Pública Federal direta, autárquica e fundacional e dá outras providências. }\end{array}$ \\
\hline & Lei n 12.305/2010: Institui a Política Nacional de Resíduos Sólidos e dá outras providências. \\
\hline & $\begin{array}{l}\text { Lei } \mathbf{n}^{\circ} \text { 12.349/2010: Alterou o art. 3 da Lei nº 8.666/1993, introduzindo o conceito de desenvolvimento nacional } \\
\text { sustentável às compras públicas e dá outras providências. }\end{array}$ \\
\hline & $\begin{array}{l}\text { Decreto } \mathbf{n}^{\mathbf{7}} \mathbf{7 . 4 0 4 / 2 0 1 0 :} \text { Estabelece normas para execução da Política Nacional de resíduos sólidos e instituiu o } \\
\text { Comitê Interministerial da Política Nacional de resíduos Sólidos. }\end{array}$ \\
\hline
\end{tabular}




\begin{tabular}{|c|c|}
\hline \multirow[t]{2}{*}{2011} & $\begin{array}{l}\text { Lei N 12.462, de 2011: Instituiu Regime Diferenciado de Contratações Públicas - RDC para os Jogos Olímpicos } \\
\text { e Paraolímpicos de 2016, Copa das Confederações da Federação Internacional de Futebol Associação Fifa } 2013 \text { e } \\
\text { Copa do Mundo de futebol de } 2014 \text {. }\end{array}$ \\
\hline & $\begin{array}{l}\text { Decreto 7.581, de 2011: Regulamenta o Regime Diferenciado de Contratações Públicas - RDC, de que trata a Lei } \\
n^{\circ} 12.462 .\end{array}$ \\
\hline \multirow{4}{*}{2012} & $\begin{array}{l}\text { Decreto n 7.746/2012: Regulamenta o art. } 3^{\circ} \text { da Lei n 8.666, de } 21 \text { de junho de 1993, para estabelecer critérios e } \\
\text { práticas para a promoção do desenvolvimento nacional sustentável nas contratações realizadas pela administração } \\
\text { pública federal direta, autárquica e fundacional e pelas empresas estatais dependentes, e institui a Comissão } \\
\text { Interministerial de Sustentabilidade na Administração Pública - CISAP. }\end{array}$ \\
\hline & Decreto n 7.794, de 2012: Instituiu a Política Nacional de Agroecologia e Produção orgânica. \\
\hline & $\begin{array}{l}\text { Instrução Normativa IBAMA } \mathbf{n}^{\circ} \mathbf{8 / 2 0 1 2 :} \text { Institui, para fabricantes nacionais e importadores, os procedimentos } \\
\text { relativos ao controle do recebimento e da destinação final de pilhas e baterias ou produto que as incorporem. }\end{array}$ \\
\hline & $\begin{array}{l}\text { Instrução Normativa SLTI/MPOG n 10/2012: Estabelece regras para elaboração dos Planos de Gestão de } \\
\text { Logística Sustentável de que trata o art. 16, do Decreto nº } 7.746 \text {, de } 5 \text { de junho de } 2012 \text {, e dá outras providências. }\end{array}$ \\
\hline 2013 & $\begin{array}{l}\text { Instrução Normativa IBAMA nº 6/2013: Dispõe sobre a regulamentação do Cadastro Técnico Federal de Atividades } \\
\text { Potencialmente Poluidoras e Utilizadoras de recursos Ambientais - CTF/APP. }\end{array}$ \\
\hline \multirow[t]{2}{*}{2014} & $\begin{array}{l}\text { Instrução Normativa SLTI/MPOG n 2/2014: Dispõe sobre regras para a aquisição ou locação de máquinas e } \\
\text { aparelhos consumidores de energia pela Administração Pública Federal direta, autárquica e fundacional e uso da } \\
\text { Etiqueta Nacional de Conservação de Energia (ENCE) nos projetos e respectivas edificações públicas federais novas } \\
\text { ou que recebam retrofit. }\end{array}$ \\
\hline & $\begin{array}{l}\text { Instrução Normativa IBAMA } \mathbf{n}^{\circ} \mathbf{2 1 / 2 0 1 4 : ~ I n s t i t u i r ~ o ~ S i s t e m a ~ N a c i o n a l ~ d e ~ C o n t r o l e ~ d a ~ O r i g e m ~ d o s ~ P r o d u t o s ~} \\
\text { Florestais - Sinaflor. }\end{array}$ \\
\hline 2015 & $\begin{array}{l}\text { Portaria MPOG n 23/2015: Estabelece boas práticas de gestão e uso de Energia Elétrica e de Água nos órgãos e } \\
\text { entidades da Administração Pública Federal direta, autárquica e fundacional e dispõe sobre o monitoramento de } \\
\text { consumo desses bens e serviços. }\end{array}$ \\
\hline 2018 & $\begin{array}{l}\text { Decreto } \mathbf{n}^{\bullet} \mathbf{9 . 3 7 3 / 2 0 1 8 : ~ D i s p o ̃ e ~ s o b r e ~ a ~ a l i e n a c ̧ a ̃ o , ~ a ~ c e s s a ̃ o , ~ a ~ t r a n s f e r e ̂ n c i a , ~ a ~ d e s t i n a c ̧ a ̃ o ~ e ~ a ~ d i s p o s i c ̧ a ̃ o ~ f i n a l ~} \\
\text { ambientalmente adequadas de bens móveis no âmbito da administração pública federal direta, autárquica e } \\
\text { fundacional. }\end{array}$ \\
\hline
\end{tabular}

\section{Fonte: Organizado pelo autor.}

Com base nas normas contidas no Quadro 1, verifica-se que a legislação nacional contempla diferentes elementos da sustentabilidade, como aqueles relacionados a logística reversa, eficiência energética, produção orgânica, recicláveis e a regulação de atividades potencialmente poluidoras.

Vale ressaltar que, algumas normas, também regulamentam formas de comprovação dos critérios e práticas sustentáveis exigidas nas especificações dos objetos demandados, com destaque para os rótulos e certificados socioambientais. Os denominados selos ambientais podem ser utilizados como meio comprobatório dos requisitos socioambientais exigidos nos instrumentos convocatórios das contratações públicas. Mas, a Administração deve preservar os princípios da isonomia e da competitividade, isto a fim de evitar impugnação dos certames. 
Ainda sobre as legislações em questão, observa-se que estas priorizam a esfera ambiental em detrimento às dimensões sociais e econômicas. Estudos, como o realizado por Gallon et al. (2019), constatam que esta preferência nas normatizações impacta na prática as contratações governamentais, pois, segundo os autores, os servidores demandantes priorizam os critérios e práticas ambientais na especificação dos objetos licitados.

Em síntese, por meio do seu poder regulatório, a Administração federal visa estabelecer política pública capaz de estimular o mercado verde, com isso incentivando ciclo virtuoso de inovações, incentivos e reduções de custos de bens, obras e serviços com aspectos sustentáveis. Portanto, os objetivos almejados com a promulgação das mencionadas legislações, ou seja, proporcionar segurança ambiental e bem-estar socioeconômico poderão ser atingidos mediante popularização das licitações positivas.

A Tabela 1 contém os dados obtidos na pesquisa documental, apresentando informações sobre as compras realizadas pelos órgãos do Poder Executivo Federal, no período de janeiro de 2014 a dezembro de 2019. Com o intuito de agregar mais informações ao estudo, os dados foram organizados por unidade da federação, demonstrando o comportamento licitatório das instituições do PEF de acordo com o Estado onde se encontram sediadas. Os valores percentuais foram aproximados para duas casas decimais.

Conforme os dados apresentados na Tabela 1, denota-se que no âmbito Brasil, as compras com itens sustentáveis (CCIS) representam apenas 0,89\% do total, com o percentual variando pouco entre os Estados, mas nenhum com grande destaque. Nos extremos, tem-se Sergipe com 2,03\% e Distrito Federal e Espírito Santo empatados com 0,63\%. No tocante aos valores, dos mais de 307 bilhões homologados, somente cerca de 860 milhões são de processos com critérios sustentáveis (PCCS), representando aproximadamente $0,28 \%$ do montante.

Tabela 1 - Dados das licitações homologadas pelo Poder Executivo Federal, nos anos de 2014 a 2019.

\begin{tabular}{|c|c|c|c|c|c|c|c|c|c|c|c|c|}
\hline $\begin{array}{c}2014 a \\
2019\end{array}$ & & Valor Total & $\begin{array}{c}\text { Processos } \\
\text { Totais }\end{array}$ & Material & Serviço & $\begin{array}{c}\text { Valor } \\
\text { ME/EPP }\end{array}$ & CCIS & & Valor PCCS & PCCS & Material & $\begin{array}{c}\text { Valor } \\
\text { ME/EPP }\end{array}$ \\
\hline Acre & $\mathrm{R} \$$ & $835.058 .523,77$ & 3.111 & $42,86 \%$ & $57,14 \%$ & $29,80 \%$ & $1,58 \%$ & $\mathrm{R} \$$ & $590.148,93$ & 49 & $100,00 \%$ & $64,08 \%$ \\
\hline Alagoas & $\mathrm{R} \$$ & $1.156 .467 .709,78$ & 5.376 & $46,03 \%$ & $53,97 \%$ & $36,06 \%$ & $1,30 \%$ & $\mathrm{R} \$$ & $963.810,08$ & 70 & $100,00 \%$ & $82,82 \%$ \\
\hline Amapá & $\mathrm{R} \$$ & $526.370 .553,07$ & 3.040 & $36,07 \%$ & $63,93 \%$ & $58,34 \%$ & $1,61 \%$ & $\mathrm{R} \$$ & $645.782,81$ & 49 & $100,00 \%$ & $99,98 \%$ \\
\hline Amazonas & $\mathrm{R} \$$ & $3.702 .408 .625,97$ & 13.339 & $42,15 \%$ & $57,85 \%$ & $45,86 \%$ & $1,33 \%$ & $\mathrm{R} \$$ & $6.601 .203,30$ & 178 & $100,00 \%$ & $56,80 \%$ \\
\hline Bahia & $\mathrm{R} \$$ & $5.264 .025 .746,22$ & 22.874 & $43,61 \%$ & $56,39 \%$ & $25,24 \%$ & $1,04 \%$ & $\mathrm{R} \$$ & $6.940 .013,18$ & 238 & $100,00 \%$ & $78,56 \%$ \\
\hline Ceará & $\mathrm{R} \$$ & $3.191 .422 .961,91$ & 12.767 & $43,56 \%$ & $56,44 \%$ & $33,60 \%$ & $0,83 \%$ & $\mathrm{R} \$$ & $2.355 .501,98$ & 106 & $100,00 \%$ & $98,86 \%$ \\
\hline $\begin{array}{l}\text { Distrito } \\
\text { Federal }\end{array}$ & $\mathrm{R} \$$ & $131.440 .974 .166,79$ & 67.570 & $38,21 \%$ & $61,79 \%$ & $6,87 \%$ & $0,63 \%$ & $\mathrm{R} \$$ & $707.342 .924,14$ & 425 & $100,00 \%$ & $1,67 \%$ \\
\hline $\begin{array}{c}\text { Espírito } \\
\text { Santo }\end{array}$ & $\mathrm{R} \$$ & $31.252 .368 .908,38$ & 19.314 & $41,88 \%$ & $58,12 \%$ & $95,49 \%$ & $0,63 \%$ & $\mathrm{R} \$$ & $1.514 .409,97$ & 122 & $100,00 \%$ & $88,53 \%$ \\
\hline
\end{tabular}




\section{Gestãoe \\ Desenvolvimento}

e-ISSN: 2446-6875

p-ISSN: 1807-5436

\begin{tabular}{|c|c|c|c|c|c|c|c|c|c|c|c|c|}
\hline Goiás & $\mathrm{R} \$$ & $3.112 .090 .483,17$ & 15.046 & $48,40 \%$ & $51,60 \%$ & $35,58 \%$ & $0,82 \%$ & $\mathrm{R} \$$ & $5.917 .965,43$ & 124 & $100,00 \%$ & $98,35 \%$ \\
\hline Maranhão & $\mathrm{R} \$$ & $2.357 .303 .844,73$ & 10.006 & $38,02 \%$ & $61,98 \%$ & $29,97 \%$ & $0,88 \%$ & $\mathrm{R} \$$ & 1.040.205,96 & 88 & $100,00 \%$ & $97,29 \%$ \\
\hline Mato Grosso & $\mathrm{R} \$$ & $3.092 .650 .833,07$ & 12.838 & $38,37 \%$ & $61,63 \%$ & $31,09 \%$ & $1,15 \%$ & $R \$$ & $5.119 .396,92$ & 148 & $100,00 \%$ & $95,99 \%$ \\
\hline $\begin{array}{c}\text { Mato Grosso } \\
\text { do Sul }\end{array}$ & $\mathrm{R} \$$ & $2.445 .690 .460,90$ & 9.628 & $46,74 \%$ & $53,26 \%$ & $40,86 \%$ & $1,42 \%$ & $\mathrm{R} \$$ & $2.938 .273,04$ & 137 & $100,00 \%$ & $98,12 \%$ \\
\hline $\begin{array}{l}\text { Minas } \\
\text { Gerais }\end{array}$ & $\mathrm{R} \$$ & $10.193 .590 .806,71$ & 70.665 & $46,84 \%$ & $53,16 \%$ & $28,78 \%$ & $0,96 \%$ & $R \$$ & $13.901 .697,34$ & 679 & $100,00 \%$ & $61,40 \%$ \\
\hline Pará & $\mathrm{R} \$$ & 4.103.848.994,32 & 27.508 & $36,67 \%$ & $63,33 \%$ & $40,42 \%$ & $1,06 \%$ & $\mathrm{R} \$$ & $9.465 .569,97$ & 291 & $100,00 \%$ & $74,00 \%$ \\
\hline Paraíba & $\mathrm{R} \$$ & $2.537 .712 .172,13$ & 15.541 & $32,50 \%$ & $67,50 \%$ & $36,51 \%$ & $1,08 \%$ & $\mathrm{R} \$$ & $1.823 .014,56$ & 168 & $100,00 \%$ & $75,60 \%$ \\
\hline Paraná & $\mathrm{R} \$$ & $6.176 .988 .870,41$ & 34.900 & $47,70 \%$ & $52,30 \%$ & $20,49 \%$ & $0,72 \%$ & $\mathrm{R} \$$ & $6.477 .018,50$ & 250 & $100,00 \%$ & $78,91 \%$ \\
\hline Pernambuco & $\mathrm{R} \$$ & $3.945 .552 .303,30$ & 24.489 & $43,45 \%$ & $56,55 \%$ & $32,02 \%$ & $1,02 \%$ & $\mathrm{R} \$$ & $31.868 .270,79$ & 251 & $100,00 \%$ & $52,15 \%$ \\
\hline Piauí & $\mathrm{R} \$$ & $1.586 .925 .880,14$ & 8.942 & $40,82 \%$ & $59,18 \%$ & $40,55 \%$ & $1,30 \%$ & $\mathrm{R} \$$ & $1.087 .142,33$ & 116 & $100,00 \%$ & $86,61 \%$ \\
\hline $\begin{array}{l}\text { Rio de } \\
\text { Janeiro }\end{array}$ & $\mathrm{R} \$$ & $41.750 .108 .960,47$ & 119.408 & $47,62 \%$ & $52,38 \%$ & $10,87 \%$ & $0,72 \%$ & $\mathrm{R} \$$ & 19.662.133,39 & 864 & $100,00 \%$ & $88,04 \%$ \\
\hline $\begin{array}{l}\text { Rio Grande } \\
\text { do Norte }\end{array}$ & $\mathrm{R} \$$ & 2.324.923.383,28 & 9.953 & $33,77 \%$ & $66,23 \%$ & $30,76 \%$ & $0,72 \%$ & $\mathrm{R} \$$ & $1.955 .243,94$ & 72 & $100,00 \%$ & $97,80 \%$ \\
\hline $\begin{array}{c}\text { Rio Grande } \\
\text { do Sul }\end{array}$ & $\mathrm{R} \$$ & $9.421 .270 .265,57$ & 46.269 & $44,49 \%$ & $55,51 \%$ & $31,25 \%$ & $0,74 \%$ & $\mathrm{R} \$$ & $6.463 .252,09$ & 341 & $100,00 \%$ & $68,55 \%$ \\
\hline Rondônia & $\mathrm{R} \$$ & $1.789 .847 .811,72$ & 7.000 & $45,08 \%$ & $54,92 \%$ & $29,85 \%$ & $1,61 \%$ & $\mathrm{R} \$$ & $3.594 .083,35$ & 113 & $100,00 \%$ & $90,56 \%$ \\
\hline Roraima & $\mathrm{R} \$$ & $1.586 .290 .752,94$ & 3.755 & $37,46 \%$ & $62,54 \%$ & $60,59 \%$ & $1,60 \%$ & $\mathrm{R} \$$ & $1.027 .049,79$ & 60 & $100,00 \%$ & $84,81 \%$ \\
\hline $\begin{array}{c}\text { Santa } \\
\text { Catarina }\end{array}$ & $\mathrm{R} \$$ & $3.818 .539 .467,50$ & 23.012 & $47,10 \%$ & $52,90 \%$ & $31,90 \%$ & $1,04 \%$ & $\mathrm{R} \$$ & $6.105 .033,18$ & 239 & $100,00 \%$ & $87,47 \%$ \\
\hline São Paulo & $\mathrm{R} \$$ & $5.470 .495 .889,50$ & 33.430 & $45,05 \%$ & $54,95 \%$ & $28,18 \%$ & $0,90 \%$ & $\mathrm{R} \$$ & $8.055 .901,63$ & 302 & $100,00 \%$ & $66,21 \%$ \\
\hline Sergipe & $\mathrm{R} \$$ & $23.379 .830 .370,25$ & 4.242 & $44,37 \%$ & $55,63 \%$ & $97,74 \%$ & $2,03 \%$ & $\mathrm{R} \$$ & $944.888,15$ & 86 & $100,00 \%$ & $98,98 \%$ \\
\hline Tocantins & $\mathrm{R} \$$ & $1.013 .190 .553,46$ & 3.709 & $34,46 \%$ & $65,54 \%$ & $39,46 \%$ & $1,27 \%$ & $\mathrm{R} \$$ & $5.380 .603,57$ & 47 & $100,00 \%$ & $99,98 \%$ \\
\hline BRASIL & R\$ & 307.475.949.299,46 & 627.732 & $46,18 \%$ & $53,82 \%$ & $29,96 \%$ & $0,89 \%$ & $\mathbf{R} \$ \varepsilon$ & 59.780.538,32 & 5.613 & $100,00 \%$ & $14,60 \%$ \\
\hline
\end{tabular}

Fonte: Portal de Compras do Governo Federal (2020).

No indicador PCCS, as instituições federais empregaram valores inferiores a um ponto percentual em todos as UF estudadas, com Pernambuco apresentando maior índice, mas com apenas 0,81\%.

Dentre as licitações sustentáveis, observa-se o destaque das ME/EPP como beneficiárias das CCIS, com elas somando elevado quantitativos dos valores homologados, com algumas UF apresentando percentuais acima dos 90\%. Mas, o consolidado nacional é bruscamente reduzido pelos dados do Distrito Federal.

Ainda dentro do conjunto das licitações positivas, destaca-se a discrepância entre as aquisições de serviços e materiais, com estes - segundo o portal - constituindo 100\% das CCIS. Este cenário, pode ser 


\section{Gestãoe \\ Desenvolvimento}

e-ISSN: 2446-6875

p-ISSN: $1807-5436$

explicado pela dificuldade de se executar o contrato de serviços sustentáveis, tendo em vista as diversas obrigações do órgão contratante.

A Figura 2 evidencia percentual de PCCS individualizado de cada um dos anos compreendidos no período investigado. Nota-se uma evolução das compras com itens sustentáveis, com o crescimento mais acentuado em 2019. No entanto, os percentuais observados ainda são incipientes.

Figura 2 - Percentual de PCCS em relação ao total licitado por ano.

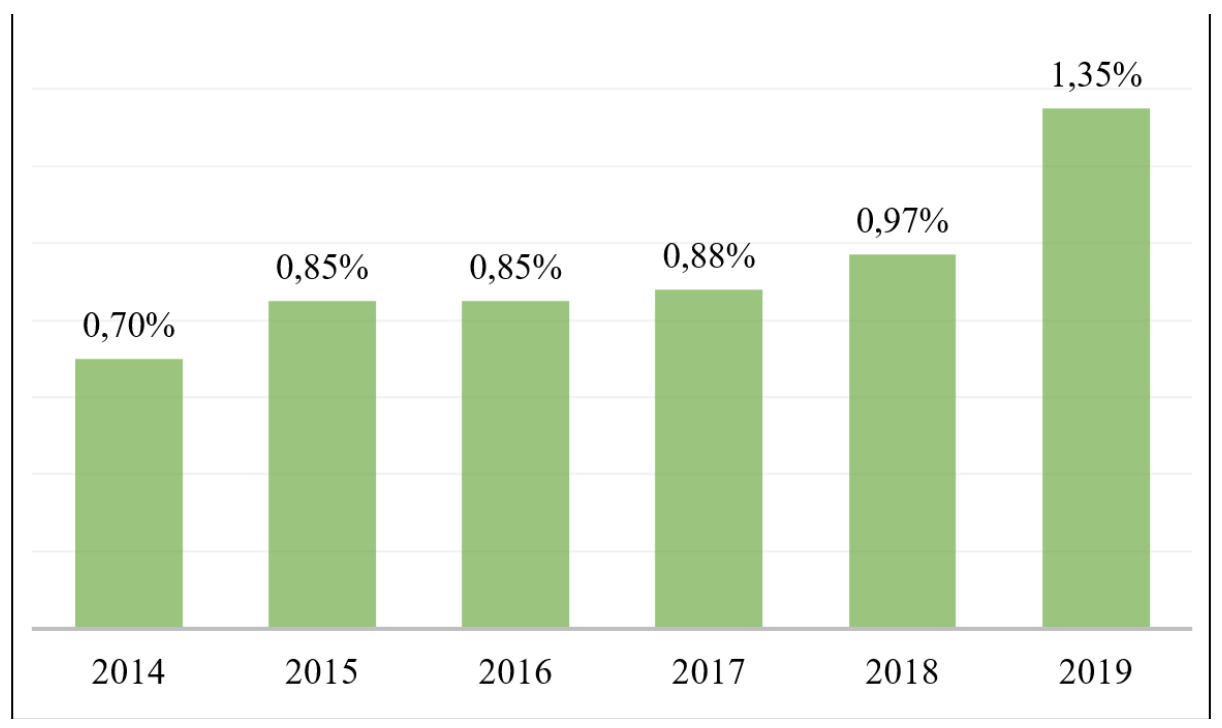

Fonte: Painel de Compras do Governo Federal (2020).

Com base nas informações contidas no Quadro, na Tabela e nas Figuras deste estudo, verifica-se que a efetivação das licitações sustentáveis, no âmbito da União, não tem acompanhado a evolução das legislações nacionais. Pois, apesar dos diferentes incentivos na esfera legal e da crescente diversificação de materiais e serviços oferecidos no mercado, as ecoaquisições ainda são pouco significativas no Brasil.

O Quadro 1, representa a constante evolução da legislação nacional, em acordo com os estudos de Betiol et al. (2012), Laloe (2014) e Oliveira e Santos (2015), pois ambos apontam no mesmo sentido. As informações contidas na Tabela 1, ao passo que trazem novos indicadores a discussão teórica, também corroboram as pesquisas que apontam as dificuldades dos órgãos públicos na efetivação das compras sustentáveis como prática regular. Em especial, o estudo promovido por Couto e Ribeiro (2016) também utilizado na fundamentação teórica deste trabalho.

Embora existam pesquisas como as realizados por Alencastro, Silva e Lopes (2014), Ornelas et al. (2018) e Ferraz (2020) sinalizando que os dados das licitações positivas se encontram subdimensionados, 
especialmente devido às especificações incorretas dos itens pretendidos. Entende-se que ainda há vasto caminho a percorrer para a efetivação de políticas públicas voltadas a promoção do DNS.

Mesmo não sendo o objeto desta pesquisa, entende-se que o distanciamento entre a previsão legal e a prática esteja relacionada aos seguintes fatores: problemas na capacitação dos atores envolvidos no processo de contratação (demandantes, pregoeiros, equipe de apoio e gestores), cultura organizacional resistente a mudanças, falta de pessoal nos órgãos, ausência de guias práticos específicos, dentre outras barreiras.

A implantação da coleta, separação e armazenamento do lixo, da logística reversa e da correta destinação dos resíduos e dos materiais recicláveis são outros desafios à Administração. Posto que, a efetivação das políticas de fomento à sustentabilidade, além da aquisição mais responsável, também inclui a destinação apropriada dos produtos descartados.

Logo, os resultados da pesquisa indicam um longo caminho a ser percorrido pela Administração pública brasileira, no tocante a implementação de políticas públicas orientadas ao desenvolvimento nacional sustentável a partir das licitações positivas.

\section{CONCLUSÕES}

A alteração no artigo $3^{\circ}$ da lei geral de licitações e contratos, pela Lei n 12.349/2010, introduziu a promoção do ecodesenvolvimento como objetivo das compras governamentais, assim ampliando o conceito de seleção da proposta mais vantajosa, outrora mais relacionado à obtenção do menor preço. Desta maneira, impondo aos gestores públicos, pregoeiros e demais atores envolvidos nos processos licitatórios a obrigação de buscarem por especificações que garantam a aquisição de produtos, serviços e obras com critérios e práticas sustentáveis.

Como contribuições, o estudo elencou algumas das principais normas sobre compras sustentáveis e reuniu dados das contratações realizadas pelo Poder Executivo Federal. Considerando as informações obtidas, verifica-se o distanciamento entre a previsão legal e aquilo que tem sido assistido nas licitações dos órgãos integrantes do PEF. Portanto, o presente estudo demonstrou a necessidade de a Administração pública adequar as suas aquisições às normas vigentes, com isso atendendo de fato às demandas legais e sociais acerca das licitações positivas.

Comparado aos volumes totais das contratações do PEF, observa-se o pequeno percentual nacional de compras sustentáveis e o baixo montante de recursos empregados na aquisição de materiais e serviços, que causam menores impactos no decorrer do seu ciclo de vida. Estes padrões são assistidos em todas as 


\section{Gestãoe \\ Desenvolvimento}

e-ISSN: 2446-6875

p-ISSN: $1807-5436$

instituições federais, independente da UF onde se encontram sediadas, o que pode ser reflexo de ausência ou insuficiência de treinamento de pessoal em âmbito nacional.

Como limitação, o estudo não focou na identificação das possíveis barreiras à efetiva implementação das CPS e em formas de superá-las. No entanto, considera-se importante pesquisas neste sentido, dado a relevância dos gastos públicos como instrumento de geração de demanda e orientação de mercado.

\section{REFERÊNCIAS}

ABREU, José Augusto A. K. Pinto. Considerações e recomendações para as Compras Públicas Sustentáveis no Brasil. Projeto Sustainable Public Procurement and Ecollabeling (SPPEL). Programa das Nações Unidas para o Meio Ambiente - PNUMA, 2016.

ALENCASTRO, Maria Alice Cruz; SILVA, Edson Vicente da; LOPES, Ana Maria D'Ávila. Contratações sustentáveis na administração pública brasileira: a experiência do Poder Executivo federal. Revista de Administração Pública, Rio de Janeiro, v. 48, n. 1, p. 207-235, jan./fev. 2014.

BETIOL, Luciana Stocco; UEHARA, Thiago Hector Kanashiro; LALOE, Florence Karine; APPUGLIESE, Gabriela Alem; ADEODATO, Sérgio; RAMOS, Lígia; MONZONI, Mario Prestes. Compra Sustentável: a força do consumo público e empresarial para uma economia verde e inclusiva. 1. ed. São Paulo: Editora FGV. Programa Gestão Pública e Cidadania, 2012.

BIDERMAN, Rachel; MACEDO, Laura Silvia Valente; MONZONI, Mario; MAZON, Rubens. Guia de compras públicas para a promoção do desenvolvimento sustentável. 2. ed. Rio de Janeiro: FGV, 2008.

BRAMMER, Stephen; WALKER, Helen. Sustainable procurement in the public sector: An international comparative study. International Journal of Operations and Production Management. v. 31, n. 4, p. 452-476, 2011

BRASIL. Decreto $n^{\circ}$ 7.746/2012, de 5 de junho de 2012. Regulamenta $\mathbf{0}$ art. $\mathbf{3}^{\circ}$ da Lei $\mathbf{n}^{\circ} \mathbf{8 . 6 6 6}$, de $\mathbf{2 1}$ de junho de 1993, para estabelecer critérios e práticas para a promoção do desenvolvimento nacional sustentável nas contratações realizadas pela administração pública federal direta, autárquica e fundacional e pelas empresas estatais dependentes, e institui a Comissão Interministerial de Sustentabilidade na Administração Pública - CISAP. Brasília, DF, 5 jun. 2012.

Instrução Normativa n 01, de 19 de janeiro de 2010 - Secretaria de Logística e Tecnologia da Informação do Ministério do Planejamento, Orçamento e Gestão (MPOG). Dispõe sobre os critérios de sustentabilidade ambiental na aquisição de bens, contratação de serviços ou obras pela Administração Pública Federal direta, autárquica e fundacional e dá outras providências. Brasília, DF, 19 jan. 2010. 


\section{Gestãoe \\ Desenvolvimento}

e-ISSN: 2446-6875

p-ISSN: $1807-5436$

Lei nº 6.938, de 31 de agosto de 1981. Dispõe sobre a Política Nacional do Meio Ambiente, seus fins e mecanismos de formulação e aplicação, e dá outras providências. Brasília, DF, 31 ago. 1981.

Lei n 8.666, de 21 de junho de 1993. Regulamenta o art. 37, inciso XXI, da Constituição Federal, institui normas para licitações e contratos da Administração Pública e dá outras providências. Brasília, DF, 21 jun. 1993.

. Lei n 9.605, de 12 de fevereiro de 1998. Dispõe sobre as sanções penais e administrativas derivadas de condutas e atividades lesivas ao meio ambiente, e dá outras providências. Brasília, DF, 12 fev. 1998.

Lei no 10.295, de 17 de outubro de 2001. Dispõe sobre a Política Nacional de Conservação e Uso Racional de Energia e dá outras providências. Brasília, DF, 17 out. 2001.

. Lei nº 11.284, de 2 de março de 2006. Dispõe sobre a gestão de florestas públicas para a produção sustentável; institui, na estrutura do Ministério do Meio Ambiente, o Serviço Florestal Brasileiro - SFB; cria o Fundo Nacional de Desenvolvimento Florestal - FNDF; altera as Leis $\mathrm{n}^{\circ} \mathrm{s} 10.683$, de 28 de maio de 2003, 5.868, de 12 de dezembro de 1972, 9.605, de 12 de fevereiro de 1998, 4.771, de 15 de setembro de 1965, 6.938, de 31 de agosto de 1981, e 6.015, de 31 de dezembro de 1973; e dá outras providências. Brasília, DF, 2 mar. 2006.

Lei no 12.187, de 29 de dezembro de 2009. Institui a Política Nacional sobre Mudança do Clima - PNMC e dá outras providências. Brasília, DF, 29 dez. 2009.

Lei $n^{\circ}$ 12.349, de 15 de dezembro de 2010. Altera as Leis $\mathbf{n}^{\text {0s }}$ 8.666, de 21 de junho de 1993, 8.958, de 20 de dezembro de 1994, e 10.973, de 2 de dezembro de 2004; e revoga o $\S 1^{\circ}$ do art. $2^{\circ}$ da Lei n 11.273, de 6 de fevereiro de 2006. Brasília, DF, 15 dez. 2010.

. Lei Complementar n 123, de 14 de dezembro de 2006. Institui o Estatuto Nacional da Microempresa e da Empresa de Pequeno Porte; altera dispositivos das Leis no 8.212 e 8.213, ambas de 24 de julho de 1991, da Consolidação das Leis do Trabalho - CLT, aprovada pelo Decreto-Lei no 5.452, de 10 de maio de 1943, da Lei no 10.189, de 14 de fevereiro de 2001, da Lei Complementar no 63, de 11 de janeiro de 1990; e revoga as Leis no 9.317, de 5 de dezembro de 1996, e 9.841, de 5 de outubro de 1999. Brasilia, DF, 14 dez. 2006.

Portal de Compras do Governo Federal. Portal de Compras. Disponivel em: <https://www.comprasgovernamentais.gov.br/>. Acesso em: 06 jan. 2020. 


\section{Gestãoe \\ Desenvolvimento}

e-ISSN: 2446-6875

p-ISSN: $1807-5436$

Portal Contratações Públicas Sustentáveis (CPSustentáveis). Disponível em: <http://cpsustentaveis.planejamento.gov.br/contratacoes-publicassustentaveis>. Acesso em: 03 jan. 2020.

CALDAS, Eduardo de Lima; NONATO, Raquel Sobral. Compras públicas e promoção do desenvolvimento local. Revista do Serviço Público, v. 64, n. 4, p. 465-480, 2013.

COMISSÃO MUNDIAL SOBRE MEIO AMBIENTE E DESENVOLVIMENTO. Nosso Futuro Comum. 2. ed. Rio de Janeiro: FGV, 1991.

COUTO, Hugo Leonnardo Gomides do; COELHO, Cristiano. Fatores críticos no comportamento do gestor público responsável por compras sustentáveis: diferenças entre consumo individual e organizacional. Revista de Administração Pública, Rio de Janeiro, v. 49, n. 2, p. 519-543, mar./abr. 2015.

COUTO, Hugo Leonnardo Gomides do; RIBEIRO, Francis Lee. Objetivos e desafios da política de compras públicas sustentáveis no Brasil: a opinião dos especialistas. Revista de Administração Pública, Rio de Janeiro, v. 50, n. 2, p. 331-343, mar./abr. 2016.

CRESWELL, John W. Investigação qualitativa e projeto de pesquisa: escolhendo entre cinco abordagens. Tradução de Sandra Mallmann da Rosa. 3. ed. Porto Alegre: Penso, 2014.

DI PIETRO, Maria Sylvia Zanella. Direito Administrativo. 29. ed. Rio de Janeiro: Forense, 2016.

FERNANDES, Campos Christo Ciro. Compras Públicas no Brasil: tendências de inovação, avanços e dificuldades no período recente. Administração Pública e Gestão Social, v. 11, n. 4, 2019.

FERRAZ, Lucas Ribeiro. Compras Públicas Sustentáveis - um estudo sobre a aquisição de materiais no campus Paracambi do Instituto Federal de Educação, Ciência e Tecnologia do Rio de Janeiro. Dissertação (mestrado). Universidade Federal Rural do Rio de Janeiro, Mestrado Profissional em Gestão e Estratégia, 2020. Disponivel em: <http://cursos.ufrrj.br/posgraduacao/ppge/defesas-de-trabalho-de-conclusao-2020/>. Acesso em: 12 mar. 2021.

GALLON, Ives; FLORES, Graziela Machado; TREVISAN, Marcelo; KNEIPP, Jordana Marques. Análise dos critérios de sustentabilidade aplicados nas licitações de uma universidade pública federal. Revista Gestão Ambiental e Sustentabilidade, v. 8, n. 2, p. 315-334, maio/ago. 2019.

GIL, Antônio Carlos. Como elaborar projetos de pesquisa. 5. ed. São Paulo: Atlas, 2010.

LALOE, Florence Karine. Arcabouço Jurídico para Compras Públicas Sustentáveis no Brasil e o uso de Rotulagem e Certificações. Projeto Sustainable Public Procurement and Ecollabeling (SPPEL). Programa das Nações Unidas para o Meio Ambiente - PNUMA, 2014. 


\section{Gestãoe \\ Desenvolvimento}

e-ISSN: 2446-6875

p-ISSN: $1807-5436$

LIMA, Carlos Eduardo de; AMÂNCIO-VIEIRA, Saulo Fabiano; ROMAGNOLO, Dayane Freire. A Inserção da Temática Sustentabilidade em um Programa Privado Stricto Sensu em Administração: o Isomorfismo Institucional como Potencializador da Mudança Organizacional. Revista Gestão e Desenvolvimento, Novo Hamburgo, v. 15, n. 1, p. 104-126, jan./jun. 2018.

MEIRELLES, Hely Lopes. Direito administrativo brasileiro. 42. ed. São Paulo: Malheiros, 2016.

NASCIMENTO, Elimar Pinheiro do. Trajetória da sustentabilidade: do ambiental ao social, do social ao econômico. Estudos Avançados, v. 26, n. 74, p. 51-64, 2012.

OLIVEIRA, Bernardo Carlos S. C. M. de; SANTOS, Luis Miguel Luzio dos. Compras públicas como política para o desenvolvimento Sustentável. Revista de Administração Pública, Rio de Janeiro, v. 49, n. 1, p. 189-206, jan./fev. 2015.

ONU - ORGANIZAÇÕES DAS NAÇÕES UNIDAS. Agenda 2030. Disponível em: <https://nacoesunidas. org/pos2015/agenda2030/>. Acesso em: 10 fev. 2020.

ORNELAS, Paulo Sérgio Rocha; BRANDÃO, Maria de Fatima do Nascimento; PEREIRA, Allan Barreto; SANTOS, Marcelo Ferreira dos; KRIIGER, Celia Cristina Pecini Von. Cadastramento de especificações nos Catálogos de compras e contratações, o Mistério dos baixos índices de efetividade e sustentabilidade nas compras governamentais. In: Anais do XXV SIMPED - Simpósio de Engenharia de Produção. Anais... Bauru (SP), 2018.

SEVERO, Eliana Andréa; DORION, Eric Charles Henri; GUIMARÃES, Julio Cesar Ferro de. Hélices Holísticas de Inovação e Ecoinovação: drivers para o desenvolvimento sustentável. Revista Gestão e Desenvolvimento, Novo Hamburgo, v. 17, n. 2, p. 57-81, maio/ago. 2020.

SUGAHARA, Cibele Roberta; RODRIGUES, Eduardo Luiz. Desenvolvimento Sustentável: um discurso em disputa. Desenvolvimento em Questão, v. 17, n. 49, p. 30-43, 17 out. 2019.

VEIGA, José Eli da. Indicadores de sustentabilidade. Estudos Avançados, v. 24, n. 68, p. 39-52, 2010. 